\title{
QUE CORPO É ESTE? \\ O PROCESSO DE SUBJETIVAÇÃO NA CONSTRUÇÃO DISCURSIVA DOS CORPOS NAS REDES SOCIAIS
}

\author{
¿QUÉ CUERPO ES ÉSTE? \\ EL PROCESO DE SUBJETIVACIÓN EN LA CONSTRUCCIÓN DISCURSIVA DE LOS \\ CUERPOS EN LAS REDES SOCIALES
}

\author{
WHAT BODY IS THIS? \\ THE PROCESS OF SUBJECTIVATION IN THE DISCURSIVE CONSTRUCTION OF \\ BODIES IN SOCIAL NETWORKS
}

\author{
Fausi dos SANTOS ${ }^{1}$ \\ Paulo Rennes Marçal RIBEIRO²
}

RESUMO: O presente artigo apresenta os diferentes efeitos de sentido produzidos pelos usuários da Internet a respeito do corpo nas redes sociais. Em primeiro lugar foi realizada uma análise discursiva e histórica dos múltiplos gestos de leitura e interpretação sobre o corpo em diferentes culturas. Em um segundo momento, com Pierre Lévy e Gilles Deleuze, o texto se desdobra a refletir os processos de subjetivação pelo qual o corpo virtual passa na veiculação das redes sociais a partir do advento das novas tecnologias digitais.

PALAVRAS-CHAVE: Corpo. Redes sociais. Discurso. Desterritorialização.

RESUMEN: El presente artículo presenta los diferentes efectos de sentido producidos por los usuarios de Internet acerca del cuerpo en las redes sociales. En primer lugar se realizó un análisis discursivo e histórico de los múltiples gestos de lectura e interpretación sobre el cuerpo en diferentes culturas. En un segundo momento, con Pierre Lévy y Gilles Deleuze, el texto se desdobla a reflejar los procesos de subjetivación por el cual el cuerpo virtual pasa en la transmisión de las redes sociales a partir del advenimiento de las nuevas tecnologías digitales.

PALABRAS CLAVE: Cuerpo. Redes sociales. Discurso. Despojo.

ABSTRACT: This article presents the different effects of meaning produced by Internet users regarding the body in social networks. In the first place, a discursive and historical analysis of the multiple gestures of reading and interpretation on the body in different cultures was carried out. In a second moment, with Pierre Lévy and Gilles Deleuze, the text unfolds to reflect the processes of subjectivation to which the virtual body passes in the transmission of social networks from the advent of new digital technologies.

KEYWORDS: Body. Social networks. Discourse. Deterritorialization.

${ }^{1}$ Instituto Toledo de Ensino (ITE), Bauru - SP - Brasil. Professor. Doutorando do Programa de Pós-graduação em Educação Escolar. Pesquisador Capes/Obeduc/Inep em Análise do Discurso. Mestre em Linguística pela UNIFRAN -. E-mail: fausifilo@ hotmail.com

${ }^{2}$ Universidade Estadual Paulista (UNESP), Araraquara - SP - Brasil. professor do Departamento de Psicologia da Educação e Coordenador do Programa de Pós-Graduação em Educação Sexual. Livre-Docente em Sexologia e Educação Sexual. ORCID: <https://orcid.org/0000-0002-1552-5702>.E-mail: paulorennes@fclar.unesp.br 


\section{Introdução}

\section{Os diferentes efeitos de sentido sobre o corpo na história.}

O corpo, este invólucro no qual o "eu” habita. Desde os primórdios a humanidade tem se dedicado a encontrar meios de entender e discursivizar o corpo. As pinturas rupestres foram, talvez, uma das mais antigas tentativas de identificar e marcar o corpo por meio do traço pictórico. Estes traços vão além da mera discrição de fatos do cotidiano, existem pinturas que revelam uma tentativa de inscrever estes corpos a uma realidade existencial. É a palma da mão no fundo da caverna como assinatura do sujeito que marca e determina sua existência e passagem pela comunidade, mãos que o inscreve no mundo com uma função social seja como, guerreiro, marido, pai, ou o liga ao sobrenatural como xamã, sacerdote ou pajé. Confere a ele como ritual de passagem um novo existir, ruptura de nível que inaugura a este corpo uma nova realidade. É o corpo eternizado, convertido em discurso de pertencimento. A palma na rocha revela "estive aqui". Rocha e tinta como instrumento de ampliação do corpo convertido em marca e identidade.

Figura 1: Pintura rupestre - Mãos humanas e Bisão - Altamira - Espanha.

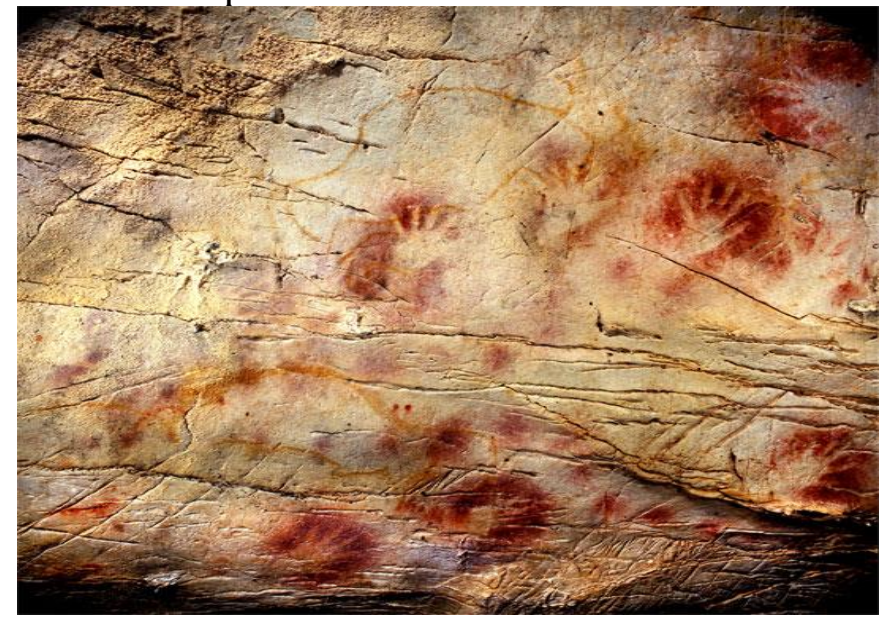

Fonte: Portal da Arte.

Com o advento da tradição oral nas primeiras comunidades humanas, foi elaborado um instrumento vital para ordenação e controle dos corpos e de suas produções, o Mito. Esta ferramenta surge como palavra Sagrada que não somente decifra os desejos e pulsões dos corpos, mas narra como estes foram concebidos e criados pelo poder divino. Basta observar o gênesis na tradição judaica, o homem sendo plasmado pelas mãos de Deus a partir da argila, 
tendo o sopro divino em suas ventas que o trouxe à vida, assim como a mulher concebida da costela do homem. ${ }^{3}$

O mito narra o surgimento do cosmos, do mundo, do homem e os porquês da existência humana. Por isso, em todas as civilizações, o mito foi o elemento decisivo na criação das instituições de poder, sejam as religiões, o governo, a justiça, a moral e a própria educação. Mito como palavra Sagrada ordenadora e ritualística que inscreve os corpos a uma ordem discursiva socialmente aceita. Mito que estabelece marcas, proibições, instaura tabus, cria valores, forma a moral e reinscreve o sujeito no mundo.

Como afirma Brandão (2001), o mito é o relato de um acontecimento ocorrido em um tempo primordial, por meio da intervenção de entes sobrenaturais que inaugura uma nova realidade. Como elemento ordenador da realidade, o mito possui o poder de criar e estabelecer uma moral, um costume ou fazer deixar de existir uma prática ou realidade social.

[...] de outro lado, o mito é sempre uma representação coletiva, transmitida através de várias gerações e que relata uma explicação do mundo. Mito é, por conseguinte, a parole, a palavra "revelada", o dito. E, desse modo, se o mito pode se exprimir ao nível da linguagem, "ele é, antes de tudo, uma palavra que inscreve e fixa um acontecimento". (BRANDÃO, 2001, p. 36)

$\mathrm{Na}$ mitologia grega existiram narrações que propunham gestos e economias de restrição ao corpo e ao sexo. Um dos mais célebres mitos da antiguidade, escrito pelo poeta Sófocles (497-406), intitulado Édipo Rei, narra a trágica história de Édipo, que deve cumprir o destino (moira) de matar o pai e casar-se com a mãe. Por mais que Édipo fuja de tal maldição acaba por cumpri-la, pois para os Gregos do destino ninguém escapa. O preço pelo parricídio e o incesto com a mãe é por um lado a loucura de Jocasta, que acaba por se enforcar, e por outro, Édipo que perfura os próprios olhos pelo fato de ter contemplado o corpo nu da mãe.

$\mathrm{O}$ sentido moral do mito sugere uma economia de proibições e inibições para as tribos gregas divididas em pequenos vilarejos. Simbolicamente trabalha com a ideia de que ninguém deve levantar a mão aos pais e muito menos tocar o corpo de um parente próximo, sob pena de maldição dos deuses.

${ }^{3}$ Gênesis, $2 ; 7$. 
Figura 2: Diálogo de Édipo com a Esfinge

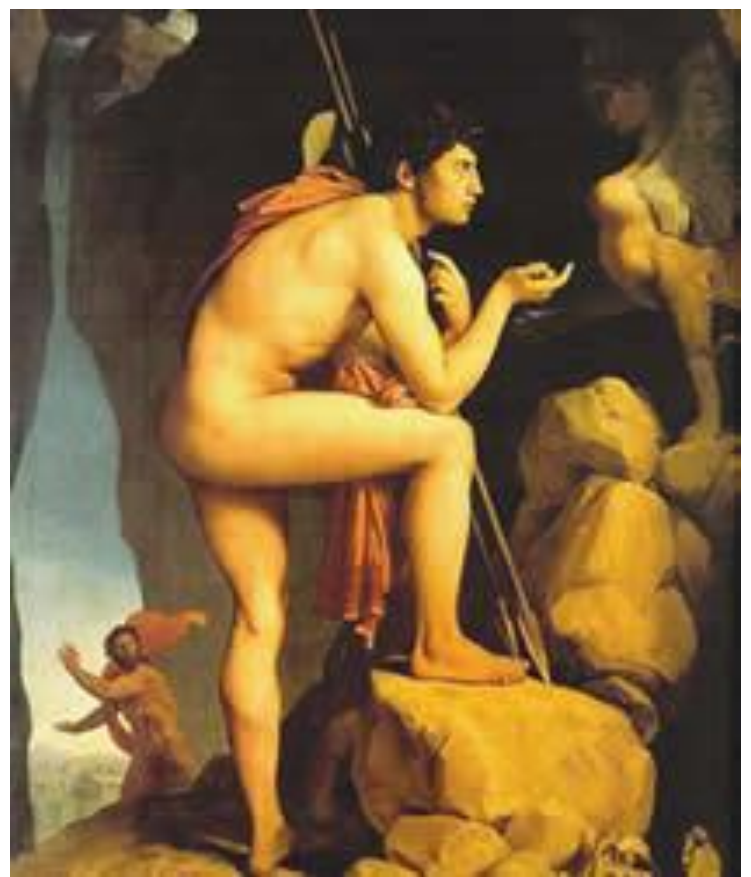

Fonte: Arquivo Wikipedia.

O Mito de Édipo é tão rico em seus efeitos de sentido que desprendeu o interesse de Sigmund Freud (1856-1939), o pai da psicanálise, que interpretou suas diferentes características ligadas ao inconsciente e desenvolveu as bases do funcionamento do aparelho cognitivo, principalmente no desenvolvimento da fase fálica associada à descoberta da sexualidade pela criança.

O corpo é múltiplo em produções de efeitos de sentido ao deixar em cada época seu traço e significado e ao trazer registrado em si o símbolo e a marca de uma época ou de um conjunto de valores. É o corpo do Rei que traz a marca do poder no manto sobre os ombros, a coroa signo do domínio sobre a cabeça e o cetro real em uma das mãos como sinal de controle e pastoreio. Ou ainda, é o corpo do guerreiro africano que no ritual de iniciação deve trazer as marcas da ruptura de nível. Sinais da quebra de uma situação anterior de criança para o corpo do homem guerreiro, pronto para a batalha e o casamento, por isso seu corpo é o templo que deve carregar os sinais de sua nova condição, sejam nas marcas do rosto feitas com ferro quente, no furo da orelha e do nariz ou ainda nas chicotadas por todo corpo que marcarão para sempre o evento de morte para uma condição anterior e o renascimento para uma situação posterior.

De fato, mesmo o corpo do homem contemporâneo também traz em si os traços dos valores e saberes de uma época, pois hoje o corpo mais do que nunca é a vitrine do sucesso ou 
do fracasso de alguém, sendo mensurado e formatado a todo instante em padrões e referenciais unívocos que devem ser almejados e desejados por todos.

A medicina, a moda e o mercado se apossam do corpo e sobre ele constroem a noção do corpo como produto. O corpo como objeto, constructo ou esboço das clínicas estéticas onde é medido, cortado e moldado. O corpo das academias que é recriado por exercícios físicos, tonificado e hipertrofiado ao extremo, ao ponto de se tomar proporções artificiais. $\mathrm{Ou}$ ainda, o corpo das dietas, que em função de uma cultura da magreza, se submete a regimes pesados e violentos que testam os limites da anorexia e da bulimia, inserindo o indivíduo em uma ditadura das disciplinas do peso.

Portanto, o corpo e suas produções marcam e criam identidades perenes em diferentes épocas por meio de discursos que estabelecem saberes e legitimam poderes. A historiadora Denise Bernuzzi de Sant'Anna escreve a esse respeito,

[...] território tanto biológico quanto simbólico, processador de virtualidades infindáveis, campo de forças que não cessa de inquietar e confortar, o corpo talvez seja o mais belo traço da memória da vida. Verdadeiro arquivo vivo, inesgotável fonte de desassossego e de prazeres, o corpo de um indivíduo pode revelar diversos traços de sua subjetividade e de sua fisiologia, mas, ao mesmo tempo, escondê-los. Pesquisar seus segredos é perceber o quanto é vão separar a obra da natureza daquela realizada pelos homens: na verdade, um corpo é sempre "biocultural", tanto em seu nível genético, quanto em sua expressão oral e gestual (SANT`ANNA, 2004, p. 3).

Por possuir essa dimensão biocultural, a história do corpo é feita de rupturas, ondulações e cismas, pois cada sociedade desenvolveu instituições (família, educação, justiça, Estado, política, etc) a fim de estabelecer determinadas relações de poder não somente para o controle sobre os corpos, mas também para orientá-los, educá-los e discipliná-los a um ideal de homem ou cidadão que cada sociedade almejava socialmente.

De fato, foram desenvolvidos em cada cultura gestos de interpretação ao corpo. Justamente pelas mudanças em sua forma, peso e desejos, que muitas vezes o faz ser um objeto de estranhamento ao próprio indivíduo que não se reconhece no próprio corpo. Esta multiplicidade de produções, que afloram e desaparecem, arrastam o indivíduo a determinadas atitudes e escolhas e o limita nos desejos e fantasias da mente. É o que dá origem a um conjunto de saberes e poderes em diferentes povos, como tentativa de racionalizar e ordenar por meio de preceitos de ensino e aprendizagem a violenta e muitas anárquica produção do corpo e de suas expressões. Gestos revestidos com técnicas específicas para controlar, ordenar, e fazer circular por meio do corpo os saberes e valores daquilo que uma determinada cultura estabelece como verdadeiro. 
Como bem afirma Denise Sant'Anna,

[...] são antigas as tentativas de minimizar os efeitos do que é desconhecido nos corpos. Da religião à ciência, passando por diferentes disciplinas e pedagogias, a vontade de manter o próprio corpo sob controle, se possível desvendando-o exaustivamente, caracteriza a história de numerosas culturas (SANT`ANNA, 2004, p. 4).

Os mecanismos de controle sobre os efeitos desconhecidos dos corpos desenvolvidos por cada cultura passam necessariamente, como bem afirma Sant'Anna, por diferentes disciplinas educativas com a função de domesticar e civilizar as pulsões e desejos primitivos. Talvez um dos mecanismos de controle mais antigos seja a religião, pois quando se analisa a relação do homem primitivo com o corpo e a sexualidade é notado o papel que os preceitos religiosos irão exercer sobre a economia do corpo.

Seria o Mundo Virtual e a conectividade com a internet uma verdadeira rebeldia a estes mecanismos de controle? De certa forma sim, na medida em que a digitalização do "eu" e de suas vontades nas redes sociais faz circular uma grande quantidade de demandas que até então se encontravam aprisionadas no universo físico, submetidas à ordem discursiva das instituições de poder. A internet produz um movimento de "descorporificação", ao projetar o usuário a um novo espaço onde tempo e localizações geográficas são anuladas, fazendo circular toda demanda daquilo que imagina, deseja ou fantasia. O corpo digital é um corpo multifacetado e recheado de efeitos de sentidos, uma vez que a liberdade do internauta de entrar e sair do universo digital, bem como de realimentar constantemente este ambiente com variados discursos daquilo que vivencia momentaneamente, quebra o monopólio moral das instituições de poder sobre o cerceamento de seu discurso.

Parece que o advento das novas tecnologias digitais inaugura um novo estado de existência ao corpo, ao lançá-lo por um campo de imanência onde circulam diferentes acontecimentos e realidades. Diferentemente do corpo na pintura, no mito, na literatura ou na religião, o corpo nas redes digitais é formado por diferentes simbolizações que oferecem a ele sentidos e uma existência própria, marcada pela desterritorialização e liquidez, onde circula no hiperespaço criando novos efeitos de sentido nos usuários. Essa condição estranha de existência conecta pessoas, emoções, sentimentos e experiências variadas, aciona vivencias até então impossíveis de serem captadas pelos órgãos sensoriais, projeta a mente para além do corpo, intensifica sensações. 


\section{Que corpo é este?}

Vale agora a questão: que corpo é este construído na rede? Primeiro vale ressaltar que o sujeito nas redes sociais é permeado por uma existência deslocada no tempo e no espaço, um sujeito marcado de transitoriedades, que salta em links no ciberespaço sendo ressignificado por usuários que acessam e discursivizam seu perfil constantemente. Por esta constatação se evidencia que o corpo na rede se torna um corpo de discursos, reconstruído pelo manuseio e ajuizamento dos internautas. O corpo físico é suporte rígido, fechado e temporalizado, mortal, submetido às leis da física e do espaço que ocupa, no entanto, uma vez inserido na rede digital, torna-se fluxo de efeitos de sentido, sendo construído textualmente em uma foto ou vídeo, toma uma dinâmica própria independente do seu dono, já que está à mercê de opiniões e críticas dos usuários.

Por isso, uma selfie de uma moça ou rapaz desnudo no espelho de seu quarto, toma efeitos de sentidos variados que transitam desde opiniões positivas e de apreciação de incentivo, até de desaprovação e sanções proibitivas impostas por outros internautas. Sua selfie destemporaliza sua identidade e a insere em uma condição de pura polissemia linguística, e o que sobra do corpo são apenas marcas, esboços de significações que se espalham infinitamente na rede, reproduzidos por internautas do mundo inteiro.

Ocupa espaços de salas de bate papo, aplicativos de compartilhamento, sites pornôs, o que torna difícil (e algumas vezes impossível) desfazer seus traços e marcas espalhados na rede. Uma vez inserido na rede, se espalha como vírus, uma metástase digital incontrolável que mesmo os servidores (Youtube, Google, etc) bloqueando os canais de acesso a tal material, outros usuários em posse do arquivo depositam em outras contas, levando novamente a uma onda de compartilhamento que em pouco tempo inunda novamente a rede com tal material.

Desta forma, o corpo na rede se inscreve em uma condição existencial própria, parcialmente imune aos efeitos da lei e da justiça, que só conseguem estabelecer controle em usuários identificados, mas que, no entanto, não conseguem acompanhar o movimento voluntário de milhões de usuários que alimentam a rede constantemente com arquivos permitidos ou não. Sendo assim, o corpo na rede é tomado de existência própria, pois ocupa diferentes espaços de enunciação produzidos pelos usuários, que o discursivizam voluntariamente.

Outra característica do que vem a ser este corpo na rede diz respeito à constatação de que, na maioria das vezes, este corpo é um corpo produzido para ser exposto. Dificilmente o 
usuário postará uma imagem de si que deprecie sua personalidade, salvo quando sua imagem é roupada e postada à mercê de sua permissão. Isto evidencia a ideia de que o corpo na rede se distancia e muito do sujeito real, pois trata-se de um recorte específico de um momento que o usuário quer compartilhar e eternizar na memória de seus seguidores e amigos. Ou seja, é um corpo posado e construído por um discurso de exposição, há uma ideologia por trás dele, um sentido de estar ali daquela forma e maneira.

O corpo na rede é um corpo imagético, discursivo, penetrado de condições históricas e de intersecções ideológicas. Acompanha de um lado o desejo voluntário do usuário que permite inserir seu corpo na rede e por outro um processo rizomático próprio da linguagem digital, que o insere em um movimento de discursividade que assujeitam a significação de seu corpo às opiniões e ajuizamento de valores daqueles que circulam na rede. É um posicionamento passivo, vulnerável daquele que se lança no mundo digital, uma vez que seu corpo se amplia no universo dos efeitos de sentido, chegando a consequências que fogem totalmente ao seu controle.

\section{Reconstrução do corpo no ciberespaço}

Pierre Lévy (2011), em sua obra $O$ que é o virtual?, destaca que as técnicas desenvolvidas pelas novas tecnologias proporcionam nos dias atuais uma grande capacidade de manipulação e ressignificação do corpo em vários segmentos, sejam eles médicos ou sociais. Dos equipamentos de visualização do interior dos tecidos orgânicos que revelam as várias camadas que constituem o corpo, dos tecidos moles até os ossos, os enxertos e próteses que misturam órgãos naturais com artificiais, criando corpos híbridos e potencializados em suas ações.

Afirma Lévy a este respeito,

[...] da socialização das funções somáticas ao autocontrole dos afetos ou do humor pela bioquímica industrial, nossa vida física e psíquica passa cada vez mais por uma "exterioridade" complicada na qual se misturam circuitos econômicos, institucionais e tecnocientíficos. (LÉVY, 2011, p. 27)

O fato é que, segundo o autor, a virtualização dos corpos que experimentamos hoje cria uma nova etapa na autocriação de si, que ressignifica o corpo e suas funções. Corpo reconstruído pelo discurso na transitoriedade digital, tendo suas funções perceptivas ampliadas e externalizadas ao extremo pelos sistemas de telecomunicação. Existem, por 
exemplo, sites que já oferecem serviços sensoriais e somáticos aos usuários, ao instalar câmeras em alta resolução de som e imagem em parques, cachoeiras e avenidas famosas com transmissão 24 horas por dia, a fim de teletransportar o internauta a uma experiência sensitiva e imagética mais real possível, despertando emoções e sensações em qualquer pessoa no mundo. Alguns serviços funerários inclusive já utilizam este serviço para transmissão de velórios em tempo real pela internet.

Para Lévy, esta ampliação das funções somáticas produz uma espécie de integração sensitiva das experiências,

[...] graças às máquinas fotográficas, às câmeras e aos gravadores, podemos perceber as sensações de outra pessoa, em outro momento e outro lugar. Os sistemas ditos de realidade virtual nos permitem experimentar, além disso, uma integração dinâmica de diferentes modalidades perceptivas. Podemos quase reviver a experiência sensorial completa de outra pessoa. (LÉVY, 2001, p. 28)

Reviver não somente experiências de outras pessoas arquivadas em vídeos ou fotografias, como também tornar viva uma experiência do aqui e agora, por meio de aplicativos em redes sociais que proporcionam a telepresença com a transmissão ao vivo do usuário. Qualquer internauta pode acompanhar em tempo real essa transmissão de um para muitos, como uma central de televisão, tudo por um toque e um acesso online.

Segundo Lévy, ocorre uma projeção do corpo do usuário pela ação e imagem, levando a uma desterritorialização do corpo que opera na rede produzindo novos efeitos de sentido e inaugurando novos acontecimentos. Afirma Lévy,

[...] os sistemas de realidade virtual transmitem mais que imagens: uma quase presença. Pois os clones, agentes visíveis ou marionetes virtuais que comandamos por nossos gestos, podem afetar ou modificar outras marionetes ou agentes visíveis, e inclusive acionar à distância aparelhos "reais" e agir no mundo ordinário. Certas funções do corpo, como a capacidade de manipulação ligada à retroação sensório-motora em tempo real, são assim claramente transferidas à distância, ao longo de uma cadeia técnica complexa cada vez mais bem controlada em determinados ambientes industriais. (LÉVY, 2011, p. 29)

Sobre a capacidade de manipulação remota de aparelhos reais, isto já se faz presente nas forças armadas de muitos países, como por exemplo, os Drones não tripulados, utilizados pelo exército norte americano, que são controlados por um operador a milhares de quilômetros de distância via realidade virtual. Ou ainda, cirurgias realizadas à distância, com cirurgiões operando robôs a quilômetros do paciente. Sem falar em sistemas de 
monitoramento remoto, que possibilita a qualquer pessoa acessar imagens de sua casa ou estabelecimento comercial por um aplicativo no celular. De fato, a projeção do corpo desterritorializado nas redes digitais vem se tornando cada vez mais presente nas ações cotidianas.

A virtualização do corpo proporciona ao usuário manipular não somente objetos remotamente, mas sua própria imagem ou avatar produzido discursivamente na rede. Em uma rede social como o Facebook ou Instagram são criadas diferentes texturas para este tipo de existência tão única, um corpo com várias peles produzido por diferentes mecanismos como filtros, enquadramentos e textos que oferecem à imagem ou vídeo do usuário múltiplos efeitos de sentido, segundo o desejo do internauta. Corpo virtual que faz circular demandas, corpo convertido em rizoma, ou como afirma Deleuze na obra Mil Platôs, um Corpo sem Órgãos recheado de multiplicidades.

Gilles Deleuze se debruçou sobre o problema do corpo enquanto intensidade, para isso criou um conceito que sintetiza toda diversidade dos campos de imanência que constituem a realidade, ao qual denominou Corpo sem Órgãos - CsO. É possível produzir para si um $\mathrm{CsO}$, onde faça circular toda a energia nômade de afetos, desejos e intensidades que compreendem o sujeito e o meio onde está inserido. Corpo sem Órgãos enquanto invólucro imaterial onde uma demanda específica da realidade é criada e concretizada, um corpo necessário para atualizar um acontecimento e fazer circular uma produção.

Nas palavras de Deleuze,

[...] um $\mathrm{CsO}$ é feito de tal maneira que ele só pode ser ocupado, povoado por intensidades. Somente as intensidades passam e circulam. Mas o $\mathrm{CsO}$ não é uma cena, um lugar, nem mesmo um suporte onde aconteceria algo. [...] O $\mathrm{CsO}$ faz passar intensidades, ele as produz e as distribui num spatium, ele mesmo intensivo, não extenso. (DELEUZE, 2004, p. 13)

Neste sentido, o CsO opera como uma condição de intensidades que faz circular uma demanda. É como um ator, que ao encarnar a personagem, precisa se desfazer de seu corpo físico, de sua personalidade e se refazer na personagem, reconstruir outra identidade a partir de intensidades estranhas à condição de sua personalidade. Somente criando para si um CsO, fará presente esta existência dentro da existência, um corpo novo, ressignificado, a personagem construída que fará circular o texto. O CsO de Deleuze é um meio por onde circula subjetivações, converte e traz à existência novos corpos, bebe no devir e dá forma a outros sujeitos provisórios. É possível fazer para si um $\mathrm{CsO}$, para fazer circular um tipo de existência determinada que atenda meus interesses e desejos. 
Ora, esta estranha existência do corpo virtual, projetado nas redes sociais, configurado em subjetivações sobre subjetivações que inauguram e destroem avatares ou perfis, não seria também um $\mathrm{CsO}$ ? Basicamente sim! Pois é o corpo intenso que acessa demandas e inaugura acontecimentos, aciona objetos, faz circular afetos e sentimentos, cria demandas discursivas. Cada usuário ao criar um perfil em redes sociais, cria para si um CsO. Cada perfil faz circular uma demanda, a começar pelo objetivo deste, seja para discursivizar a vida e os afazeres diários, o trabalho, a política, a arte ou até mesmo para fazer circular suas fantasias mais íntimas. Seja qual for o objetivo, sempre há uma intensidade a tomar forma e ser posta em circulação na rede. Um mesmo usuário pode construir para si vários $\mathrm{CsO}$ no mundo virtual, um mosaico de corpos prontos a colocar em movimento diferentes tipos de agenciamentos que produzem e amplificam subjetividades, dão forma à discursos.

É um hipercorpo com texturas diferentes, no qual, em cada camada um tipo de demanda é acionada a fim de dar conta de uma necessidade ou desejo. Pierre Lévy afirma que o hipercorpo pode ser visto incialmente nos transplantes que criam uma grande circulação de órgãos entre corpos humanos,

[...] os implantes e as próteses confundem a fronteira entre o que é mineral e o que está vivo: óculos, lentes de contato, dentes falsos, silicone, marcapassos, próteses acústicas, implantes auditivos, filtros externos funcionando como rins sadios. [...] Cada corpo individual torna-se parte integrante de um imenso hipercorpo híbrido e mundializado. (LÉVY, 2011, $\mathrm{p}, 30-31)$

Mas o mundo virtual também se torna hipercorpo, na medida em que cria uma aldeiamento dos corpos virtuais que comungam experiências similares, acionam acontecimentos, criam uma verdadeira globalização de realidades compartilhadas em sites de relacionamento de todos os tipos. Próteses discursivas de tradutores automáticos que faz a barreira da língua se anular, jogos on-line que criam verdadeiras tribos com indivíduos de nacionalidades diferentes, compartilhamento de arquivos que geram um intenso tráfego de informações, gerenciamento de conhecimento em redes específicas de cultura e arte. Ou seja, dá origem ao hipercórtex que expande, segundo Lévy, seus axônios pelas redes digitais do planeta, "o hipercorpo da humanidade estende seus tecidos quiméricos entre as epidermes, entre as espécies, para além das fronteiras e dos oceanos, de uma margem a outra do rio da vida." (LÉVY, 2011, p. 31)

No passado o hipercorpo era metafórico, apenas possibilidade, com o aperfeiçoamento da técnica se tornou real (transplantes, etc), com o advento do mundo digital 
ampliou e se transformou em hiperconectividade. Corpos compartilhados e simbolizados, manipulados e ressignificados.

\section{Considerações finais}

É absolutamente evidente que o ser humano tem se dedicado a entender o corpo e suas produções desde as primeiras comunidades e povoamentos. Diferentes instrumentos, como as pinturas rupestres, bem como o mito e até a arte tentaram discursivizar o corpo e criar mecanismos de controle sobre seus efeitos de sentido. Não existe propriamente um corpo, mas sim múltiplas leituras e mecanismos de poder na história que moldaram e criaram significados diferentes ao corpo. Cada cultura ao seu modo criou um tipo de corpo específico ao cidadão que desejava. Daí a importância das diferentes instituições de poder (Governo, Religião, Família, Educação, etc), que articularam regimes disciplinares específicos sobre o corpo e seus significados.

Neste contexto, com o advento das novas tecnologias digitais, o corpo foi ressignificado discursivamente. As redes sociais com as diferentes interfaces patrocinam a desterritorialização do corpo, convertendo-o em marcas digitais, corpo virtual, que circula no hiperespaço fazendo surgir diferentes intensidades ao bel prazer e desejo dos usuários. $\mathrm{O}$ corpo na rede é rizoma, feito de várias entradas e saídas que colocam em movimento afetos e uma multiplicidade de demandas.

Segundo Lévy, na rede o corpo se transforma em hipercorpo, onde tem ampliando sua projeção ao alcançar tribos e grupos espalhados em todos os lugares e ao globalizar percepções com outros corpos a nível mundial. As diversas ferramentas que as redes sociais oferecem criam próteses utilizadas por internautas para construir ou ampliar a percepção e impacto dos perfis ou avatares produzidos digitalmente.

Deleuze, e o seu conceito de Corpo sem Órgãos, que é um corpo de múltiplas intensidades, pode ser interpretado como o estado de existência que os corpos ocupam nas redes sociais. Existência virtual, desterritorializada e que ocupa um plano de imanência, inaugurando acontecimentos e sendo discursivizados pelos usuários. O $\mathrm{CsO}$ das redes sociais é um corpo múltiplo de infinitas possibilidades de ressignificação. 


\section{REFERÊNCIAS}

BRANDÃO, J. de S. Mitologia Grega. Petrópolis: Vozes, 2001.

DELEUZE, G.; GUATTARI, F. Mil Platôs: capitalismo e esquizofrenia. v. 3. São Paulo: Editora 34, 2004.

LÉVY, Pierre. O que é o Virtual? São Paulo: Editora 34, 2011.

SANT’ANNA, D. B. Políticas do corpo. São Paulo: Estação Liberdade, 1995.

\section{Como referenciar este artigo}

SANTOS, F.; RIBEIRO, P. R. M. Que corpo é este? O processo de subjetivação na construção discursiva dos corpos nas redes sociais. Doxa: Rev. Bras. Psico. e Educ., Araraquara, v. 20, n. 1, p. 52-64, jan./jun., 2018. e-ISSN: 2594-8385. DOI: 10.30715/rbpe.v20.n1.2018.11263

Submetido em: 02/04/2018

Aprovado em: 18/05/2018 